OPEN ACCESS

Edited by:

Gary T. Hardiman,

Medical University of South Carolina,

United States

Reviewed by:

Luxian Lv,

Second Affiliated Hospital of Xinxiang

Medical University, China

Piotr Podlasz,

University of Warmia and Mazury,

Poland

${ }^{*}$ Correspondence:

Weihua Yue

dryue@bjmu.edu.cn

${ }^{t}$ These authors have contributed equally to this work

Specialty section: This article was submitted to

Psychopharmacology,

a section of the journal

Frontiers in Psychiatry

Received: 08 April 2020 Accepted: 12 June 2020

Published: 02 July 2020

Citation:

Liao J, Wang N, Ma M, Lu T, Yan H and Yue W (2020) C677T Polymorphism in the MTHFR Gene Is Associated With Risperidone-Induced Weight Gain in Schizophrenia. Front. Psychiatry 11:617. doi: 10.3389/fpsyt.2020.00617

\section{C677T Polymorphism in the MTHFR Gene Is Associated With Risperidone-Induced Weight Gain in Schizophrenia}

\author{
Jingping Liao ${ }^{1,2,3 \dagger}$, Ning Wang ${ }^{4 \dagger}$, Mengying Ma ${ }^{1,2}$, Tianlan $L u^{1,2}$, Hao Yan ${ }^{1,2}$ \\ and Weihua Yue ${ }^{1,2,3,5^{*}}$
}

1 Institute of Mental Health, The Sixth Hospital, Peking University, Beijing, China, ${ }^{2}$ National Clinical Research Center for Mental Disorders \& Key Laboratory of Mental Health, Ministry of Health (Peking University) \& Chinese Academy of Medical Sciences Research Unit (No.2018RU006), Beijing, China, ${ }^{3}$ School of Nursing, Peking University, Beijing, China, ${ }^{4}$ Center for Biological Psychiatry, Beijing HuilongGuan Hospital, Bejijing, China, ${ }^{5}$ PKU-IDG/McGovern Institute for Brain Research, Peking University, Beijing, China

Objective: To explore the association of methylenetetrahydrofolate reductase (MTHFR) C677T polymorphism with risperidone-induced weight gain.

Methods: We analyzed the association between MTHFR C677T polymorphism and risperidone-induced weight gain in 356 schizophrenia patients. The patients were treated with risperidone for 8 weeks. The height and body weight of the patients were measured before and 8 weeks after risperidone treatment. Blood DNA was genotyped for MTHFR C677T polymorphisms.

Results: We found a significant association between MTHFR C677T polymorphism and body mass index (BMI) change after 8-week risperidone treatment. The BMl of carriers with different genotypes of MTHFR gene increased over 2-8 weeks. After 8 weeks of risperidone treatment, BMl added value $\left(\mathrm{kg} / \mathrm{m}^{2}\right)$ of CC or CT genotype carriers was significantly higher than that of TT genotype carriers [CC (4.47 \pm 1.09$)$, CT (4.54 \pm 1.27$)$, $\Pi(2.31 \pm 0.75), F=5.634, P=0.001]$. Based on whether the rate of weight gain from baseline at 8 weeks of treatment exceeded $7 \%$, it was divided into a weight gain group $(n=61)$ and a non-weight gain group $(n=295)$. The $C$ allele frequency was significantly different between the two groups (48.4\% vs 32.4\%, $\chi^{2}=11.342, \mathrm{P}=0.001$ ).

Conclusion: MTHFR C677T polymorphism was associated with risperidone-induced weight gain in Chinese Han population.

Keywords: schizophrenia, risperidone medications, MTHFR, antipsychotic, weight gain

\section{INTRODUCTION}

Schizophrenia is a chronic, complex, and severe mental disorder, affecting approximately $1 \%$ of the general population. Schizophrenia treatments are commonly accompanied by various adverse side effects (1). With the prevailing use of atypical antipsychotics or second-generation antipsychotics (SGAs), the adverse effects such as weight gain and metabolic abnormalities have become a major 
issue in the treatment of with SGAs. Antipsychotic-induced weight gain may not only adversely affect treatment adherence and clinical outcomes, but also is associated with reduced quality of life, social stigma, and greater cardiovascular morbidity and mortality (2-4).

Susceptibility to antipsychotic-induced weight gain varies substantially between individuals in ways that cannot be fully explained by differences in drug effects or other environmental factors. Thus, genetic factors are strongly implicated, and researches have been conducted to find possible associations between many genetic polymorphisms and antipsychotic-induced weight gain (5). The genetic factors which were commonly reported to be involved in antipsychotic-induced weight gain include polymorphisms in genes for $\operatorname{HTR2C}(6), 5-H T 2 A(7,8), M C 4 R$ (9), Leptin (10), FTO (11), and BDNF (12).

Genetic variants of the methylenetetrahydrofolate reductase (MTHFR) gene was also proposed as a potential candidate for antipsychotic-induced weight gain (13-15). MTHFR gene exerts an important role in folate/homocysteine metabolism that convert 5,10-methylenetetrahydrofolate to 5-methyltetrahydrofolate, which is used in methionine synthesis from homocysteine. The single-nucleotide polymorphisms (SNPs) rs1801133 (C677T) and rs1801131 (A1298C), two most important SNPs of MTHFR gene, are known to affect the function of enzymes and have shown potential clinical significance. The MTHFR gene C677T polymorphism can decrease their corresponding enzymes activities (16), which ultimately lead to enhanced plasma total homocysteine concentration and decreased folate concentration (17-19). Previous literatures have reported lower folate or higher homocysteine levels in obesity/overweight subjects compared with normal weight controls (20-22). It indicated that MTHFR C677T polymorphism might be one of genetic factors involved in antipsychotic-induced weight gain. However, the mechanisms underlying these observations remained unclear.

Recently, some studies investigated the association of MTHFR C677T polymorphism with antipsychotic-induced weight gain (15, 23). A previous research suggested that the MTHFR C677T polymorphism might, along with other genetic risk factors, provided a useful marker for the side effect of antipsychotic druginduced weight gain (15). However, another study did not detect the influence of MTHFR C677T polymorphisms on antipsychoticinduced weight gain (23). Thus, these results are conflicting and the relationship between MTHFR C677T polymorphisms and antipsychotic-induced weight gain needs to be further clarified. Besides, the research about the association of MTHFR C677T polymorphism with weight gain caused by one single antipsychotic such as risperidone is rare. In the present study, we examined the association of the MTHFR C677T polymorphism with risperidone-induced weight gain in patients with schizophrenia.

\section{MATERIALS AND METHODS}

\section{Subjects}

This study was an open clinical trial of risperidone monotherapy for 8 weeks. Oral administration was adopted, starting at $1 \mathrm{mg} / \mathrm{d}$, and dosage was added within 2 weeks to reach the therapeutic dose of 2-6 mg/d. All participants were not allowed to use any other antipsychotics, antidepressants, anxiolytics, or mood stabilizers during the study period. If the patients have severe sleep disturbances, benzodiazepines can be used intermittently at night for short periods. Height and weight of the patients were measured before and 8 weeks after treatment, and body mass index $\left(\mathrm{BMI} ; \mathrm{kg} / \mathrm{m}^{2}\right)$ was calculated as weight $(\mathrm{kg}) /$ height $(\mathrm{m})^{2}$. The Medical Ethics Committee of Institute of Mental Health, Peking University approved this study. This study was conducted in accordance with the Declaration of Helsinki. All participants were informed about the objectives and procedures and written informed consent was obtained.

All subjects were schizophrenics from outpatient and/or inpatient departments. Patients included in this research are required to meet the following inclusion criteria: (1) Chinese Han descents; (2) meeting the diagnostic criteria of schizophrenia on the basis of the Diagnostic and Statistical Manual of Mental Disorders, 4th edition (DSM-IV); (3) age ranged from 18 to 65 years, gender unlimited; (4) total score of positive and negative symptom scale (PANSS) $\geq 60$. The exclusion criteria were as follows: (1) pregnant, lactating or menopausal women; (2) patients with psychoactive substance abuse or other severe mental illness; (3) suffering from severe and unstable physical diseases such as diabetes, thyroid disease, hypertension.

\section{Genotyping}

Five milliliters of peripheral blood samples from all subjects were collected in tubes containing EDTA as an anticoagulant and stored at $4^{\circ} \mathrm{C}$. Genomic DNA was extracted from the samples using a Qiagen QIAamp ${ }^{\circledR}$ DNA Mini Kit (Qiagen $\mathrm{GmbH}$, Hilden, Germany) within one week, and stored at $-70^{\circ} \mathrm{C}$ for later use. The MTHFR C677T polymorphism was genotyped by the direct DNA sequencing method. The sequences of the primers were as follows: 5' AGC CCA GCC ACT CAC TGT TTT $3^{\prime}$ and 5' CAG CGA ACT CAG CAC TCC A 3'. The PCR amplification was carried out in a $25 \mu$ l volume containing 10 $\mathrm{mM}$ Tris- $\mathrm{HCl}$ (pH 8.3), $50 \mathrm{mM} \mathrm{KCl}, 1.5 \mathrm{mM} \mathrm{MgCl} 2,200 \mu \mathrm{M}$ of each dNTP, $0.4 \mu \mathrm{M}$ of each primer, $1 \mathrm{U}$ of Taq DNA polymerase and 30-50 ng genomic DNA. The PCR amplification conditions were: an initial denaturation at $94^{\circ} \mathrm{C}$ for $5 \mathrm{~min}$, followed by 35 amplification cycles at $94^{\circ} \mathrm{C}$ for $30 \mathrm{~s}, 64^{\circ} \mathrm{C}$ for $30 \mathrm{~s}, 72^{\circ} \mathrm{C}$ for 1 $\mathrm{min}$, and then elongation at $72^{\circ} \mathrm{C}$ for $10 \mathrm{~min}$. For SNP rs 1801133 , the PCR products were sequenced by DNA sequencing after cleaning the PCR product using BigDye Terminator Cycle Sequencing Ready Reaction Kit with Ampli-Taq DNA polymerase (Perkin Elmer, USA). The inner primers were used for the cycle-sequencing reaction, and fragments were separated by electrophoresis on an ABI PRISM genetic analyzer (Applied Biosystem).

\section{Statistical Analyses}

All statistical analyses were performed using the SPSS software (SPSS-16.0 Inc., Chicago, IL, USA). Hardy-Weinberg equilibrium (HWE) for genotype distribution was performed using a $\chi^{2}$ goodness-of-fit test. Analysis of covariance was used to examine the correlation between the baseline values and changes 
of BMI and MTHFR C677T site. Results were considered significant at two-tailed $\mathrm{p}<0.05$. P-values at two-tailed $<0.05$ were considered significant.

\section{RESULTS}

\section{Participant Characteristics}

A total of 387 patients were enrolled in the group, and 31 patients withdrew from this study due to poor efficacy (4 individuals), withdrawal of informed consent (2 individuals), violation of protocol (18 individuals), loss of follow-up (5 individuals), or other reasons ( 2 individuals). There were 356 patients who actually completed 8 weeks of medication, including 190 males and 166 females, with an average age of $30.5 \pm 10.3$ years. The mean therapeutic dose of risperidone was $4.8 \pm 1.2 \mathrm{mg} / \mathrm{d}$.

\section{HWE}

According to the HWE, there was no significant difference between the observed value and expected value of genotype frequency for MTHFR C677T (rs1801133) polymorphism. Thus, it suggested that the subjects were collected randomly from the general population. The population was randomly mated, and there were neither migration nor risk of selection bias.

\section{Association Analysis of MTHFR C677T Polymorphism With Risperidone-Induced Weight Gain}

There was no significant difference in baseline BMI $\left(\mathrm{kg} / \mathrm{m}^{2}\right)$ before risperidone treatment among the three genotype carriers of MTHFR C677T polymorphism [CC $(22.15 \pm 3.43)$, CT $(21.15 \pm 4.02)$, TT (22.18 \pm 3.53$), \mathrm{F}=1.778, \mathrm{P}=0.169$ ], but there were significant differences after 2, 4, and 8 weeks of treatment. The BMI of carriers with different genotypes of MTHFR gene increased over 2-8 weeks. After 8 weeks of risperidone treatment, BMI added value $\left(\mathrm{kg} / \mathrm{m}^{2}\right)$ of CC or CT genotype carriers was higher than that of TT genotype carriers, with statistically significant differences [8 weeks after treatment, BMI added value of CC $(4.47 \pm 1.09)$, CT $(4.54 \pm$ 1.27), $\mathrm{TT}(2.31 \pm 0.75), \mathrm{F}=5.634, \mathrm{P}=0.001]$ (Table 1 and Figure 1 ). Based on whether the rate of weight gain from baseline at 8 weeks of treatment exceeded $7 \%$, it was divided into a weight gain group $(\mathrm{n}=$ $61)$ and a non-weight gain group $(n=295)$. The $C$ allele frequency was significantly different between the two groups (48.4\% vs $32.4 \%$, $\left.\chi^{2}=11.342, \mathrm{P}=0.001, \mathrm{OR}=1.93,95 \% \mathrm{CI}=1.54-2.37\right)$ (Table 2).

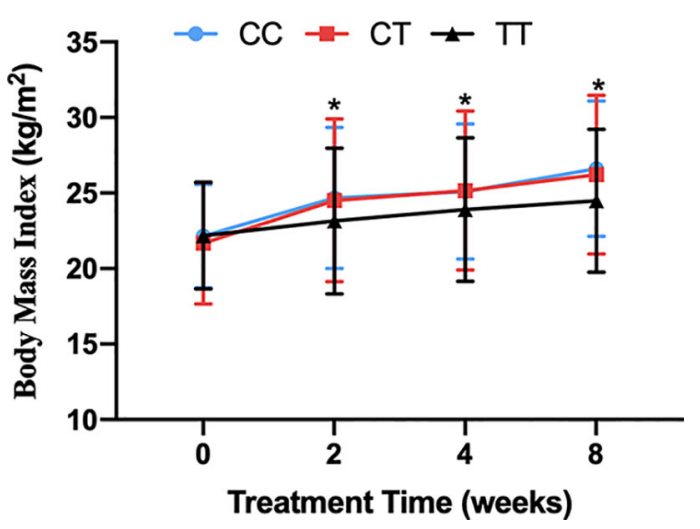

FIGURE 1 | The BMI of carriers with CC, CT and TT genotypes of MTHFR C677T polymorphism during the 8-week risperidone treatment. There was no significant difference in BMI of three genotype carriers before risperidone treatment. However, the BMl of carriers with three genotypes of MTHFR gene increased over 2-8 weeks. After 2, 4, and 8 weeks of risperidone treatment, $\mathrm{BMl}$ added value of CC or CT genotype carriers was significantly higher than that of $\Pi$ genotype carriers. Asterisks indicate that there are significant differences among BMl of CC, CT, and TT genotype carriers.

\section{DISCUSSION}

Currently, atypical antipsychotic medications such as risperidone, olanzapine, and quetiapine are the first-line drugs for the treatment of schizophrenia. With their widespread use in clinical practice, the problem of drug-induced weight gain has received more and more attention (4). Until now, the specific mechanism of weight gain caused by antipsychotics is unclear. However, previous studies have shown that genetic factors may be closely related to this process. Different individuals may have large differences in weight gain even when taking the same drug of the same dose (5). There are a large number of reports about the susceptible genes related to weight gain caused by antipsychotics. However, these researches were mainly focused on candidate genes related to the target of antipsychotics, such as DRD2 and HTR2C (8). Recently, there have been more and more studies about genes which affect energy metabolism and carbohydrate metabolism such as leptin and its receptor (LEP, $L E P R$ ) gene, and explore their association with weight gain caused by antipsychotics (24). These findings provide new ideas to study the mechanism of weight gain caused by antipsychotics.

This study suggested that, during the acute risperidone treatment, the MTHFR C677T C allele carriers were more

TABLE 1 | Association of MTHFR C677T polymorphism with risperidone-induced weight gain in schizophrenia.

\begin{tabular}{|c|c|c|c|c|c|}
\hline & CC & CT & TT & $F(d f=2)$ & p-value \\
\hline $\mathrm{N}(\%)$ & $62(17.4)$ & $165(46.5)$ & $129(36.1)$ & N.A. & N.A. \\
\hline Sex (male/female) & $32 / 30$ & $84 / 81$ & $65 / 64$ & 0.987 & 0.464 \\
\hline Age (years) & $24.2 \pm 7.3$ & $23.3 \pm 6.8$ & $22.7 \pm 6.4$ & 0.976 & 0.578 \\
\hline Baseline BMI $\left(\mathrm{kg} / \mathrm{m}^{2}\right)$ & $22.15 \pm 3.43$ & $21.68 \pm 4.02$ & $22.18 \pm 3.53$ & 1.778 & 0.169 \\
\hline 2-Week BMI Change from Baseline $\left(\mathrm{kg} / \mathrm{m}^{2}\right)$ & $2.53 \pm 0.32$ & $2.84 \pm 0.84$ & $0.97 \pm 0.14$ & 5.412 & $<0.001$ \\
\hline 4-Week BMI Change from Baseline $\left(\mathrm{kg} / \mathrm{m}^{2}\right)$ & $2.95 \pm 1.12$ & $3.48 \pm 1.25$ & $1.72 \pm 0.66$ & 6.398 & $<0.001$ \\
\hline 8-Week BMI Change from Baseline $\left(\mathrm{kg} / \mathrm{m}^{2}\right)$ & $4.47 \pm 1.09$ & $4.54 \pm 1.27$ & $2.31 \pm 0.75$ & 5.634 & 0.001 \\
\hline
\end{tabular}

df, degrees of freedom; N.A., not applicable. 
TABLE 2 | Comparison of MTHFR C677T genotype and allele frequency between groups with and without significant weight gain (\%)

\begin{tabular}{lcccc}
\hline $\begin{array}{l}\text { MTHFR } \\
\text { C677T }\end{array}$ & $\begin{array}{c}\text { Weight gain } \\
\text { group } \\
\mathbf{n = 6 1}\end{array}$ & $\begin{array}{c}\text { Non-weight gain } \\
\text { group } \\
\mathbf{n = 2 9 5}\end{array}$ & $\chi^{\mathbf{2}(\mathbf{d f})}$ & $\mathbf{p}$-value \\
\hline Genotype, $\mathbf{n}(\%)$ & & & & \\
CC & $15(24.6)$ & $30(10.2)$ & 12.099 & 0.002 \\
CT & $29(47.5)$ & $131(44.4)$ & $(2)$ & \\
TT & $17(27.9)$ & $134(45.4)$ & & \\
Allele, $\mathbf{n}(\%)$ & & & & \\
C & $59(48.4)$ & $191(32.4)$ & 11.342 & 0.001 \\
T & $63(51.5)$ & $399(67.6)$ & $(1)$ & \\
\hline
\end{tabular}

df, degrees of freedom.

likely to show a tendency to drug-induced weight gain than TT homozygous carriers. A previous study in 2014 analyzed the association of MTHFR C677T polymorphism with antipsychotic-induced weight gain for Chinese Han $(n=182)$ and Spanish Caucasians $(n=72)$ schizophrenia patients (15). It found that patients with the 677 CC genotype had a significantly greater BMI increasement compared to T-allele carriers in both Chinese and Spanish population. Even though this study found MTHFR polymorphism was associated with weight gain induced by antipsychotics, the sample size of this study was relatively small. Moreover, initial antipsychotic drug treatment for Chinese Han patients primarily consisted of risperidone $(n=114)$ and chlorpromazine $(n=60)$; only eight patients received clozapine, fluphenazine, or sulpiride. That meant the 182 schizophrenia patients received different types of antipsychotics. Therefore, the research about the association between MTHFR polymorphism and weight gain caused by single antipsychotics is rare. Our study confirmed that the individual differences in weight gain caused by risperidone, a first-line atypical antipsychotic, might be affected by MTHFR polymorphism.

The precise mechanism by which C677T polymorphism in the MTHFR gene to influence weight gain induced by risperidone remains unclear. As mentioned before, MTHFR exerts an important role in folate/homocysteine metabolism. The C677T polymorphism may decrease the activity of MTHFR, leading to the increase of serum homocysteine level. Homocysteine plays a key role in cell metabolism because it participates in the transfer of methyl groups in the activated methyl cycle. This cycle is in charge of global and gene promoter-specific DNA methylation, which is one of several epigenetic mechanisms involved in gene expression regulation $(25,26)$. Some researchers postulated that increased levels of homocysteine might influence weight gain via epigenetic control of gene expression in body fat storage regulation (27-29). Therefore, the possible mechanism is that MTHFR C677T polymorphism results in decreased DNA methylation of genes involved in the regulation of body weight (15).

However, this study has several limitations. Firstly, the sample size may not be sufficient. Therefore, further studies are needed to enroll more participants to confirm the present findings in our study. Secondly, side effects of drugs are not determined by a single gene, but by the interaction of multiple genes at different loci. Therefore, further studies are encouraged to explore the effect of gene-gene interaction on risperidoneinduced weight gain. Thirdly, despite the influence of the genotype of SNP rs1801133 on weight gain induced by risperidone in schizophrenia, the specific mechanism is unclear. Moreover, our current results were limited to the Chinese Han population and we also did not further clarify the relationship between other SNPs in the MTHFR gene and risperidone-induced weight gain.

In conclusion, the MTHFR C677T polymorphism showed significant associations with risperidone-induced weight gain in 356 patients of Chinese Han ancestry treated with risperidone. Due to the large ethnic differences in MTHFR C677T polymorphism, the results of drug genetic association in the Chinese Han population might help clinical precision medicine in the future. If researches could find the relationship between antipsychotics and other susceptible genes, and further explore the relationship between drug-induced metabolic syndrome and cognitive and social function, it will be helpful for clinical application. In addition, the specific neurobiological mechanism of genetic polymorphisms affecting drug-induced weight gain needs to be further explored, and long-term follow-up, and validation in different and larger populations will be required in further studies.

\section{DATA AVAILABILITY STATEMENT}

The original contributions presented in the study are publicly available. This data can be found here: https://opendata.pku.edu. $\mathrm{cn} /$ dataset.xhtml?persistentId=doi:10.18170/DVN/FBWPVH.

\section{ETHICS STATEMENT}

The studies involving human participants were reviewed and approved by the Ethical Committee of Institute of Mental Health, Peking University. The patients/participants provided their written informed consent to participate in this study.

\section{AUTHOR CONTRIBUTIONS}

WY provided the funds and designed the study. JL and NW analyzed the data and wrote the draft of the manuscript. MM recruited schizophrenia patients. TL collected peripheral blood samples. HY supervised this study.

\section{FUNDING}

The study was funded by the National Key R\&D Program of China (2016YFC1307000), National Natural Science Foundation of China (81825009, 81901358, 81221002), Peking University Clinical Scientist Program supported by "the Fundamental Research 
Funds for the Central Universities" (BMU2019LCKXJ012), Academy of Medical Sciences Research Unit (2019-I2M-5-006); PKUHSC-KCL Joint Medical Research (BMU2020KCL001), Beijing Science and Technology Commission (D171100007017002).

\section{REFERENCES}

1. Nasrallah HA. Atypical antipsychotic-induced metabolic side effects: insights from receptor-binding profiles. Mol Psychiatry (2008) 13(1):27-35. doi: 10.1038/sj.mp.4002066

2. Casey DE, Haupt DW, Newcomer JW, Henderson DC, Sernyak MJ, Davidson M, et al. Antipsychotic-induced weight gain and metabolic abnormalities: implications for increased mortality in patients with schizophrenia. J Clin Psychiatry (2004) 65(Suppl 7):4-20.

3. Vancampfort D, Stubbs B, Mitchell AJ, De Hert M, Wampers M, Ward PB, et al. Risk of metabolic syndrome and its components in people with schizophrenia and related psychotic disorders, bipolar disorder and major depressive disorder: a systematic review and meta-analysis. World Psychiatry (2015) 14(3):339-47. doi: 10.1002/wps.20252

4. Lett TAP, Wallace TJM, Chowdhury NI, Tiwari AK, Kennedy JL, Müller DJ. Pharmacogenetics of antipsychotic-induced weight gain: review and clinical implications. Mol Psychiatry (2012) 17(3):242-66. doi: 10.1038/mp.2011.109

5. Foster A, Miller DD, Buckley P. Pharmacogenetics and schizophrenia. Clin Lab Med (2010) 30(4):975-93. doi: 10.1016/j.cll.2010.07.010

6. Zhang JP, Lencz T, Zhang RX, Nitta M, Maayan L, John M, et al. Pharmacogenetic Associations of Antipsychotic Drug-Related Weight Gain: A Systematic Review and Meta-analysis. Schizophr Bull (2016) 42(6):1418-37. doi: 10.1093/schbul/sbw058

7. Reynolds GP. Pharmacogenetic Aspects of Antipsychotic Drug-induced Weight Gain - A Critical Review. Clin Psychopharmacol Neurosci (2012) 10 (2):71-7. doi: 10.9758/cpn.2012.10.2.71

8. Kao ACC, Müller DJ. Genetics of antipsychotic-induced weight gain: update and current perspectives. Pharmacogenomics (2013) 14(16):2067-83. doi: $10.2217 /$ pgs.13.207

9. Czerwensky F, Leucht S, Steimer W. MC4R rs489693: a clinical risk factor for second generation antipsychotic-related weight gain? Int J Neuropsychopharmacol (2013) 16(9):2103-9. doi: 10.1017/s1461145713000849

10. Shen J, Ge W, Zhang J, Zhu HJ, Fang Y. Leptin -2548g/a gene polymorphism in association with antipsychotic-induced weight gain: a meta-analysis study. Psychiatr Danubina (2014) 26(2):145-51.

11. Song X, Pang L, Feng Y, Fan X, Li X, Zhang W, et al. Fat-mass and obesityassociated gene polymorphisms and weight gain after risperidone treatment in first episode schizophrenia. Behav Brain Functions : BBF (2014) 10(1):35. doi: $10.1186 / 1744-9081-10-35$

12. Fonseka TM, Tiwari AK, Gonçalves VF, Lieberman JA, Meltzer HY, Goldstein $\mathrm{BI}$, et al. The role of genetic variation across IL-1 $\beta$, IL-2, IL- 6 , and BDNF in antipsychotic-induced weight gain. World J Biol Psychiatry (2015) 16(1):4556. doi: 10.3109/15622975.2014.984631

13. Ueland PM, Hustad S, Schneede J, Refsum H, Vollset SE. Biological and clinical implications of the MTHFR C677T polymorphism. Trends Pharmacol Sci (2001) 22(4):195-201. doi: 10.1016/s0165-6147(00)01675-8

14. Kuzman MR, Müller DJ. Association of the MTHFR gene with antipsychoticinduced metabolic abnormalities in patients with schizophrenia. Pharmacogenomics (2012) 13(8):843-6. doi: 10.2217/pgs.12.64

15. Srisawat U, Reynolds GP, Zhang ZJ, Zhang XR, Arranz B, San L, et al. Methylenetetrahydrofolate reductase (MTHFR) 677C/T polymorphism is associated with antipsychotic-induced weight gain in first-episode schizophrenia. Int J Neuropsychopharmacol (2014) 17(3):485-90. doi: $10.1017 / S 1461145713001375$

16. Frosst P, Blom HJ, Milos R, Goyette P, Sheppard CA, Matthews RG, et al. A candidate genetic risk factor for vascular disease: a common mutation in methylenetetrahydrofolate reductase. Nat Genet (1995) 10(1):111-3. doi: 10.1038/ng0595-111

\section{ACKNOWLEDGMENTS}

We thank the patients who generously agreed to participate in this medical study.

17. Pereira AC, Schettert IT, Morandini Filho AA, Guerra-Shinohara EM, Krieger JE. Methylenetetrahydrofolate reductase (MTHFR) c677t gene variant modulates the homocysteine folate correlation in a mild folate-deficient population. Clin Chim Acta Int J Clin Chem (2004) 340(1-2):99-105. doi: 10.1016/j.cccn.2003.09.016

18. Dankner R, Chetrit A, Murad H, Sela BA, Frystyk J, Raz I, et al. Serum adiponectin is associated with homocysteine in elderly men and women, and with 5,10methylenetetrahydrofolate reductase (MTHFR) in a sex-dependent manner. Metabol: Clin Exp (2010) 59(12):1767-74. doi: 10.1016/j.metabol.2010.05.001

19. Martin YN, Salavaggione OE, Eckloff BW, Wieben ED, Schaid DJ, Weinshilboum RM. Human methylenetetrahydrofolate reductase pharmacogenomics: gene resequencing and functional genomics. Pharmacogenet Genomics (2006) 16 (4):265-77. doi: 10.1097/01.fpc.0000194423.20393.08

20. Marchesini G, Manini R, Bianchi G, Sassi S, Natale S, Chierici S, et al. Homocysteine and psychological traits: a study in obesity. Nutr (Burbank Los Angeles County Calif) (2002) 18(5):403-7. doi: 10.1016/s0899-9007(01)00803-6

21. Jacques PF, Bostom AG, Wilson PW, Rich S, Rosenberg IH, Selhub J. Determinants of plasma total homocysteine concentration in the Framingham Offspring cohort. Am J Clin Nutr (2001) 73(3):613-21. doi: 10.1093/ajen/73.3.613

22. Martos R, Valle M, Morales R, Cañete R, Gavilan MI, Sánchez-Margalet V. Hyperhomocysteinemia correlates with insulin resistance and low-grade systemic inflammation in obese prepubertal children. Metabol: Clin Exp (2006) 55(1):72-7. doi: 10.1016/j.metabol.2005.07.008

23. Kao AC, Rojnic Kuzman M, Tiwari AK, Zivkovic MV, Chowdhury NI, Medved V, et al. Methylenetetrahydrofolate reductase gene variants and antipsychotic-induced weight gain and metabolic disturbances. J Psychiatr Res (2014) 54:36-42. doi: 10.1016/j.jpsychires.2014.03.012

24. Brandl EJ, Frydrychowicz C, Tiwari AK, Lett TAP, Kitzrow W, Büttner S, et al. Association study of polymorphisms in leptin and leptin receptor genes with antipsychotic-induced body weight gain. Prog Neuropsychopharmacol Biol Psychiatry (2012) 38(2):134-41. doi: 10.1016/j.pnpbp.2012.03.001

25. Fuks F. DNA methylation and histone modifications: teaming up to silence genes. Curr Opin Genet Dev (2005) 15(5):490-5. doi: 10.1016/j.gde.2005.08.002

26. Williams KT, Schalinske KL. New insights into the regulation of methyl group and homocysteine metabolism. J Nutr (2007) 137(2):311-4. doi: 10.1093/jn/ 137.2.311

27. Fan S-J, Yang B-Y, Zhi X-Y, He M, Wang D, Wang Y-X, et al. Are MTHFR C677T and MTRR A66G Polymorphisms Associated with Overweight/ Obesity Risk? From a Case-Control to a Meta-Analysis of 30,327 Subjects. Int J Mol Sci (2015) 16(6):11849-63. doi: 10.3390/ijms160611849

28. Terruzzi I, Senesi P, Fermo I, Lattuada G, Luzi L. Are genetic variants of the methyl group metabolism enzymes risk factors predisposing to obesity? J Endocrinol Invest (2007) 30(9):747-53. doi: 10.1007/bf03350812

29. Lewis SJ, Lawlor DA, Nordestgaard BG, Tybjaerg-Hansen A, Ebrahim S, Zacho J, et al. The methylenetetrahydrofolate reductase C677T genotype and the risk of obesity in three large population-based cohorts. Eur J Endocrinol (2008) 159(1):35-40. doi: 10.1530/eje-08-0056

Conflict of Interest: The authors declare that the research was conducted in the absence of any commercial or financial relationships that could be construed as a potential conflict of interest.

Copyright (c) 2020 Liao, Wang, Ma, Lu, Yan and Yue. This is an open-access article distributed under the terms of the Creative Commons Attribution License (CC BY). The use, distribution or reproduction in other forums is permitted, provided the original author(s) and the copyright owner(s) are credited and that the original publication in this journal is cited, in accordance with accepted academic practice. No use, distribution or reproduction is permitted which does not comply with these terms. 